\title{
New Direction: Mediation Analysis in Perinatal Epidemiological Studies
}

\author{
Gary Kong ${ }^{1}$ and Qun Miao ${ }^{2 *}$ \\ ${ }^{1}$ Faculty of Arts and Science, Queen's University, Canada \\ ${ }^{2}$ CHEO Research Institute, Canada
}

*Corresponding author: Qun Miao, CHEO Research Institute, Canada

Received Date: January 28, 2020

Published Date: February 19, 2020

\begin{abstract}
In traditional epidemiology, a multivariable regression model is often applied to evaluate the relationship between an exposure and an outcome while adjusting for confounders and taking into account of interactions. In 1992, Robins and Greenland introduced the mediator counterfactual framework concept, which has helped researchers disentangle the complex causal pathway between exposure and outcome. In the past one decade, mediation analysis has been used in various epidemiological studies, including reproductive and perinatal research. This analysis method has been incorporated into various statistical software packages, including the CAUSALMED procedure in SAS, among various others. Mediation analysis is not only used to explain causal relationships between exposure, mediator, interaction and outcome but also provide solid evidence for decision makers to implement policy.
\end{abstract}

Keywords: Mediator; Mediation analysis; Exposure; Outcome; Confounder; Interaction

Abbreviations: CHD: Congenital Heart Disease; ART: Assisted Reproductive Technology; CDE: Controlled Direct Effect; MI: Mediated Interaction; RI: Reference Interaction; PIE: Pure Indirect Effect

\section{Introduction}

In traditional epidemiological studies, exposure, outcome, confounders and interactions are variables used to examine an association between a risk factor and outcomes in a multivariable regression model [1]. An exposure variable refers to a factor that we want to examine if this factor has an association with an outcome variable. A confounder is a variable that is associated with both an exposure and an outcome but is not in the direct exposure and outcome causal pathway. If the association between an exposure and an outcome differs by levels of a third variable, this third variable is called interaction [1]. Traditional analysis methods usually only involve one statistical analysis model to examine the relationship between exposure and outcome while adjusting for confounders and taking account of potential interactions [1].

In 1992, Robins and Greenland published a paper to introduce a new concept, called mediator counterfactual framework [2]. They brought the concept of mediators in the causal relationship between exposure and outcome [2]. Unlike confounders, mediators are in the middle of causal relationship pathway between exposure and outcome Figure 1 [2]. The effect of an exposure on an outcome is mediated by another variable (or mediator) [2]. The total effect of exposure includes two parts: direct and indirect effects [3]. Later on, VanderWeele developed a four-way decomposition concept and method to further interpret the effects of interaction and mediator in the causal pathway [4]. The 4-way decomposition concept is composed of: controlled direct effect (CDE): the effect of an exposure when the mediator does not exist; a reference interaction (RI) means the interaction that plays a role if the mediator is present but exposure does not exist; a mediated interaction (MI) which means that the interaction that exists if the exposure causes the change of the mediator; a pure indirect effect (PIE) means that the effect of the mediator when an exposure does not exist times the effect of the exposure on the mediator [4]. This concept allows researchers to further differentiate the effects of exposures, interactions, and mediators while adjusting for confounders [4] [Figure 1]. 


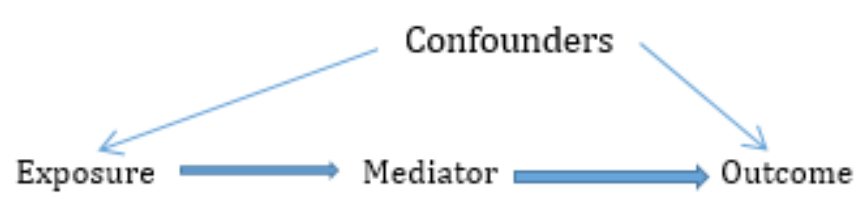

Figure 1: Causal pathway in mediation analysis.

\section{Discussion}

\section{Mediation analysis in prenatal epidemiological studies}

Mediators and mediation analysis have been used in psychology and social science studies for long time [2,5]. Mediator causal pathway and mediation analysis were introduced to epidemiological studies this decade [3]. In reproductive and perinatal research, an increasing number of researchers have adopted this concept and analysis method. Using key words of "mediation", "mediator", "ART (Assisted reproductive technology)" and "pregnancy outcome" "birth outcome", over 20 papers in perinatal epidemiological studies in the past five years can be found. Among them, at least four published studies have found that twining is a mediator in the relationship between ART and pregnancy complications or adverse birth outcomes [6-9]. Twin birth has contributed to from $17 \%$ to $91 \%$ of associations in the studies conducted in USA and Sweden [7,9]. In one recent study using population data from Ontario, Canada, the researchers found twining contributed to $87 \%$ of association between ART and congenital heart disease among infants [10]. All these results support the fact that singleton pregnancy may be preferable for the ART derived pregnancy. Mediation analysis in perinatal studies has provided decision makers solid evidence which could show a direction for policy implement.

\section{Statistical methods and software}

Mediation analysis can be performed using several software tools including SAS, R, STATA and SPSS etc. [11] In the most recent SAS 9.4 version, the CAUSALMED procedure is available for mediational analysis. Three parts of SAS output generated from this analysis, 1) modeling information, 2)summary of estimation of causal mediation effects including total effect, controlled direct effect, natural direct effect, natural indirect effect, percentage mediated, percentage due to interaction and percentage eliminated and 3) various decompositions of total effect including Four-Way decomposition [12]. There are limitations of the CAUSALMED procedure. Only one mediator in one model can be analyzed. The exposure and mediators have to be either continuous or binary variables [12]. The outcome variable has to be binary, continuous or count [12]. For multiple mediators, we have to use other methods and software packages [Table].

Table 1: Summary of recent published studies to examine relationship between ART and CHD.

\begin{tabular}{|c|c|c|c|c|c|c|}
\hline Authors & Year of publication & Exposure & Outcome & Models & $\begin{array}{c}\text { Finding of mediator } \\
\text { effect or percentage } \\
\text { of effect mediated by } \\
\text { twinning }\end{array}$ & $\begin{array}{l}\text { Study population's } \\
\text { country }\end{array}$ \\
\hline $\begin{array}{l}\text { Benedum et } \\
\text { al. [6] }\end{array}$ & 2015 & ART & $\begin{array}{l}\text { Neural Tube } \\
\text { Defects }\end{array}$ & $\begin{array}{l}\text { Logistic regres- } \\
\text { sion }\end{array}$ & Yes & USA \\
\hline $\begin{array}{l}\text { Liberman et } \\
\text { al. [7] }\end{array}$ & 2017 & ART & Birth defects & $\begin{array}{l}\text { Log-binomial, re- } \\
\text { gression models }\end{array}$ & $36 \%$ & USA \\
\hline Oberg et al. [9] & 2018 & ART & $\begin{array}{l}\text { Multiple ad- } \\
\text { verse maternal } \\
\text { and prenatal } \\
\text { outcomes }\end{array}$ & $\begin{array}{l}\text { Logistic regres- } \\
\text { sion }\end{array}$ & $17 \%$ to $91 \%$ & Sweden \\
\hline Tan et al. [8] & 2019 & ART & $\begin{array}{c}\text { severe maternal } \\
\text { morbidities }\end{array}$ & $\begin{array}{l}\text { Logistic regres- } \\
\text { sion }\end{array}$ & Not reported & China \\
\hline Wen et al. [10] & 2020 & ART & $\begin{array}{c}\text { Congenital } \\
\text { heart diseases }\end{array}$ & $\begin{array}{l}\text { Logistic regres- } \\
\text { sion }\end{array}$ & $87 \%$ & Canada \\
\hline
\end{tabular}




\section{Conclusion}

Mediation analysis is a useful and promise method, which could help us to further understand complex path causal way between exposure and outcome. More researchers have started to apply mediation analysis in reproductive and perinatal epidemiological studies. Mediation analysis is not only used to explain causal relationships between exposure, mediator, interaction and outcome but also to help us to implement policy.

\section{Acknowledgement}

The authors thank Dr. Shi Wu Wen for his permission to use the example in his study and thank Dr. VanderWeele for his mediation analysis seminar.

\section{Conflict of Interest}

The authors declare no conflict of interest exists.

\section{References}

1. Dicker RC (2006) Principles of Epidemiology in Public Health Practice. Cdc Glossary of Epidemiology Terms.

2. Robins JM, Greenland S (1992) Identifiability and exchangeability for direct and indirect effects. Epidemiology 3(2): 143-155.

3. Richiardi L, Bellocco R, Zugna D (2013) Mediation analysis in epidemiology: Methods, interpretation and bias. Int J Epidemiol 42(5): 1511-1519.
4. VanderWeele TJ (2014) A unification of mediation and interaction: a four-way decomposition. Epidemiology 25(5): 749-761.

5. Hicks R, Tingley D (2011) Causal mediation analysis. Stata J 11: 605-619.

6. Benedum CM, Yazdy MM, Parker SE, Mitchell AA, Werler MM (2016) Association of Clomiphene and Assisted Reproductive Technologies with the Risk of Neural Tube Defects. Am J Epidemiol 183(11): 977-987.

7. Liberman RF, Getz KD, Heinke D, Luke B, Stern JE et al. (2017) Assisted Reproductive Technology and Birth Defects: Effects of Subfertility and Multiple Births. Birth Defects Res 109(14): 1144-1153.

8. Tan J, Qi YN, Zhang J, Wang W, Zhang GT et al. (2019) The mediation effect of multiple gestations on the association between in vitro fertilisation and severe maternal morbidities: A retrospective cohort study. BMJ Open 9(7): e022670.

9. Oberg AS, Vander Weele TJ, Almqvist C, Hernandez-Diaz S (2018) Pregnancy complications following fertility treatment-disentangling the role of multiple gestation. Int J Epidemiol 47(4): 1333-1342.

10. Wen SW et al. Associations of assisted reproductive technology derived pregnancies and the risk of infants with congenital heart diseases. Manuscript preparation for publication.

11. Valeri L, VanderWeele TJ (2013) Mediation analysis allowing for exposure-mediator interactions and causal interpretation: Theoretical assumptions and implementation with SAS and SPSS macros. Psychol Methods 18(2): 137-150.

12. Yung Y, Lamm M, Zhang, W (2018) Causal Mediation Analysis with the CAUSALMED Procedure. 